\title{
Knowledge of hypertension and its management among hypertensive patients on chronic medicines at primary health care public sector facilities in South Africa; findings and implications
}

\author{
Rampamba EM ${ }^{1}$, Meyer JC ${ }^{1}$, Helberg E ${ }^{1}$, Godman B ${ }^{2,3,4}$ \\ ${ }^{1}$ School of Pharmacy, Sefako Makgatho Health Sciences University, Ga-Rankuwa, Pretoria, \\ 0208, South Africa. Emails: mrampamba@gmail.com; hannelie.meyer@smu.ac.za; \\ elvera@mweb.co.za \\ ${ }^{2}$ Division of Clinical Pharmacology, Karolinska Institute, Stockholm, Sweden. Email: \\ Brian.Godman@ki.se \\ ${ }^{3}$ Strathclyde Institute of Pharmacy and Biomedical Sciences, University of Strathclyde, \\ Glasgow, United Kingdom. Email: Brian.godman@strath.ac.uk \\ ${ }^{4}$ Health Economics Centre, Liverpool University Management School, Liverpool, United \\ Kingdom. Email: Brian.Godman@liverpool.ac.uk
}

\begin{abstract}
*Author for correspondence: Brian Godman, Division of Clinical Pharmacology, Karolinska Institute, Karolinska University Hospital Huddinge, SE-141 86, Stockholm, Sweden. Email: Brian.Godman@ki.se; Telephone: +46 8 58581068. Fax: +46 859581070 and Strathclyde Institute of Pharmacy and Biomedical Sciences, University of Strathclyde, Glasgow G4 0RE, United Kingdom. Email: brian.godman@strath.ac.uk.
\end{abstract}

(Accepted for Publication - Expert Review of Cardiovascular Therapy - Please keep CONFIDENTIAL)

\begin{abstract}
Background: High and growing prevalence rates of hypertension in South Africa. Consequently, there is a need to assess knowledge and management among hypertensive patients receiving chronic medication from primary health care (PHC) facilities in South Africa as a basis for improving future management. This is important as South Africa seeks to improve its management of chronic diseases. Method: Descriptive, quantitative study amongst chronic hypertensive patients in the chronic disease programme. Patients were interviewed face-to-face by trained pharmacists using a structured questionnaire. Data analysis included descriptive and inferential statistics. Results: Half (53.7\%) of the patients had uncontrolled BP. Less than a third of patients $(27.7 \%)$ knew what hypertension is, the meaning of recorded BP numbers (4.5\%), and what normal BP should be (19.9\%). All patients who knew the meaning of BP numbers had formal education ( $\mathrm{p}=0.047$ ). Only $15.6 \%$ of the $56.0 \%$ patients, who received hypertension information, received it on antihypertensive medicines specifically. Conclusions: Majority of the patients lacked hypertension specific knowledge and only half had controlled BP. Interventions to improve the control of high BP should be targeted at closing knowledge gaps as part of the current chronic treatment initiatives to ensure the benefits of increased access to care are realized.
\end{abstract}

Keywords: Chronic medication, hypertension, knowledge, primary health care, South Africa

\section{Introduction}

Globally, non-communicable diseases (NCDs) account for $63 \%$ of disease burden [1], with deaths caused by NCDs rising up to $70 \%$ by 2020 [1, 2], and high blood pressure (BP) associated with up to 9.4 million deaths annually and rising [3-5]. Presently, three out of four 
patients with hypertension live in low and middle income countries (LMICs), accounting for nearly $80 \%$ of total deaths, with the highest prevalence in Africa [4-7].

The burden of NCDs in South Africa (SA) has increased in the past decade, with mortality due to NCDs similar across SA [2]. Currently, the public health care system in SA is faced with major challenges due to Human Immunodeficiency Virus (HIV) and Acquired Immune Deficiency Syndrome (AIDS), tuberculosis (TB), injury and violence, maternal and child health related issues as well as NCDs like hypertension and diabetes [8], with up to $70 \%$ of women and a third of men overweight or obese [9]. Published estimates suggest up to $78 \%$ of those aged 50 or older have hypertension [10], with hypertensive diseases now the seventh underlying cause of death and a major contributor to cardiovascular disease in SA [11]. Hypertension also accounts for the greatest reason why patients with NCDs visit primary health care (PHC) facilities in SA [12].

Inadequate management of hypertension is the result of a number of factors including a lack of resources and lifestyle modifications, non-adherence to medication, and a lack of understanding of the disease [7,13-19], with non-adherence rising in low and middle income countries (LMIC) due to lack of resources and access [7]. Patients who have hypertension knowledge can participate in the management of their disease [7,20-22], with the inability to read and interpret medication instructions and BP readings contributing to uncontrolled BP [23-25]. Evidence has also shown that little or no education increases the possibility of having hypertension or its complications [22,24-26].

To ensure universal health coverage for all South Africans, the government introduced the National Health Insurance (NHI) in 2012 to unfold over the next 14 years [27,28], designed to provide access to affordable quality health services for all based on their health needs, irrespective of their socio-economic status [27]. To improve the availability and accessibility of medicines to patients with chronic diseases, the government has recently introduced the Central Chronic Medicines Dispensing and Distribution (CCMDD) programme [27,28]. Patients who are stable on treatment would visit health care facilities at 6-monthly intervals for a clinical assessment. Monthly prescriptions are collected from the health care facility, or from a registered pick-up point, to enhance access, aiming to improve retention and adherence [28].

However, even though medicines are free to treat hypertension, it was found that the majority of hypertensive patients on chronic treatment at PHC facilities are not well controlled [19]. The lack of hypertension specific knowledge and the lack of literacy among hypertensive patients, similar to other studies, were suggested as possible reasons for uncontrolled hypertension in SA [19,21-26].

\section{Aims}

This study aimed to build on previous studies to determine current knowledge among hypertensive patients collecting their chronic medication from PHC facilities in South Africa. This is important for the successful implementation of NHI and CCMDD programmes.

\section{Method}

\subsection{Study setting}

The study was conducted at 50 PHC facilities, which included 42 PHC clinics and eight community health care $(\mathrm{CHC})$ centres in the Vhembe District of Limpopo Province, which is 
one of the NHI pilot districts in SA for the CCMDD programme. Health care services in the district are delivered by district hospitals, PHC facilities and mobile services in four subdistricts. Primary care is typically the first point of contact that patients have with the public health care service in SA, with $84 \%$ of the population treated in the public system [12].

\subsection{Study design}

A descriptive, quantitative operational study was conducted among chronic hypertensive patients collecting their medication from PHC facilities in the Vhembe District.

\subsection{Study population and sample}

Convenient and consecutive sampling was used to recruit between one and 15 hypertensive patients at each of the $50 \mathrm{PHC}$ facilities as part of normal facility operations. This resulted in a final sample of 253 patients. Patients were recruited either before or after the collection of their medicines, after consultation with the nurse or medical practitioner, as long as their vital signs such as blood pressure (BP) and weight had been taken by one of the health care staff. The inclusion criteria were adult patients $\geq 18$ years, patients on chronic antihypertensive treatment, the ability to speak and understand English, Tshivenda or Tsonga, and willingness to participate in the study. Patients with complications based on their noted clinical characteristics such as pregnancy-related hypertension, patients with secondary hypertension, kidney or liver failure were excluded from this study. Exclusion criteria were identified by the examining nurse or medical practitioner. No attempt was made to document the number of patients not meeting the inclusion criteria since the focus was on recruiting patients for the study.

\subsection{Data collection procedures and data collection instrument}

Data were collected over a three-month period, between June and August 2015. A structured questionnaire was administered in a face-to-face interview by trained pharmacists visiting the PHC facilities as part of routine practice to assess patients' knowledge on hypertension and its management. The questionnaire was developed and adapted based on questionnaires used in other studies [29-31], after which it was pretested among 20 hypertensive patients on treatment prior to the commencement of the study, to ascertain the suitability and feasibility of the questionnaire for the specific study population. Subsequently, a few amendments were made to the questionnaire, based on the respondents' interpretation and understanding of the questions. As a result, enhance the robustness and validity of the questionnaire.

Patients' responses were recorded on the questionnaire. Physical measurements of BP, taken on the day of the interview as part of normal practices were recorded from the patients' files. Resting BP was typically measured by nurses trained on the procedure, with measurement on either arm either using a digital automatic BP monitor, in one third of clinics, or a sphygmomanometer, in two thirds of clinics, depending on availability. A mobile stadiometer and a column standing scale, with patients wearing light clothing and no shoes, were used to measure height and weight respectively. Patients were asked about their social habits, which included how many times in a week or month they drink alcohol without requesting the unit of alcohol or number of alcoholic drinks, and whether they smoked. If so, how many cigarettes they smoke per day.

\subsection{Data analysis}

Data were captured on Microsoft Excel ${ }^{\mathrm{TM}}$ spread sheets, checked for correctness and discrepancies rectified prior to data analysis. Statistical analyses were performed on SAS version 9.4. Data were summarised by frequency counts and percentages for the categorical variables and subgroups. Means with standard deviation (SD) and medians with quartiles (Q) 
were calculated for continuous variables. Hypertensive patients with formal education and those without were compared in terms of hypertension knowledge. Statistical tests were twosided and $p$-values $\leq 0.05$ were considered significant. Responses to open-ended questions were manually categorised to enable the counting of responses within the different categories, and summarised as frequency counts and percentages.

\subsection{Ethical considerations}

Ethical clearance for the study was obtained from the Medunsa Research Ethics Committee of the University of Limpopo (currently Sefako Makgatho Health Sciences University) before commencement of the study (MREC/H/ 27/2014: PG). Permission to conduct the study was obtained from the Limpopo Department of Health and Vhembe District Executive Manager. All patients provided written informed consent to participate in the study. Each patient was allocated a unique study number and no personal details were recorded.

\section{Results}

\subsection{Socio-demographic and clinical characteristics}

The socio-demographic and clinical characteristics of the patients, distributed by gender, are presented in Table 1. All study patients $(\mathrm{n}=253)$ were black Africans, with a mean age of 62.7 (SD: 13.6$)$ years and females predominating $(81.9 \%)$. The vast majority $(86.6 \%)$ of the 112 patients (where weight was recorded had a body mass index (BMI) above normal $(>25)$ with a mean and median BMI of 31.8 (SD 7.4) and 30.5 (Q1:26.6; Q3:34.6) respectively (Table 1).

Table 1: Socio-demographic and clinical characteristics of patients by gender

\begin{tabular}{|c|c|c|c|c|}
\hline \multirow{2}{*}{\multicolumn{2}{|c|}{ Patient characteristics }} & \multirow{3}{*}{$\begin{array}{c}\text { Female } \\
\text { No }(\%) * \\
2(0.8) \\
\end{array}$} & \multirow{3}{*}{$\begin{array}{c}\text { Male } \\
\text { No }(\%) * \\
0 \\
\end{array}$} & \multirow{3}{*}{$\begin{array}{c}\text { Total } \\
\text { No }(\%) * \\
2(0.8) \\
\end{array}$} \\
\hline & & & & \\
\hline \multirow[t]{7}{*}{ Age group (years) } & Up to 30 & & & \\
\hline & $31-40$ & $7(3.0)$ & 0 & $7(3.0)$ \\
\hline & $41-50$ & $27(11.4)$ & $4(1.7)$ & $31(13.1)$ \\
\hline & $51-60$ & $53(22.4)$ & $9(3.8)$ & $62(26.2)$ \\
\hline & $61-70$ & $63(26.6)$ & $16(6.8)$ & $79(33.3)$ \\
\hline & $>70$ & $42(17.7)$ & $14(6.0)$ & $56(23.6)$ \\
\hline & Total & $194(81.9)$ & $43(18.1)$ & $237(100.0)$ \\
\hline \multirow[t]{5}{*}{ Education } & None & $113(46.9)$ & $22(9.1)$ & $135(56.0)$ \\
\hline & Primary education & $55(22.8)$ & $13(5.4)$ & $68(28.2)$ \\
\hline & Secondary education & $25(10.4)$ & $5(2.1)$ & $30(12.5)$ \\
\hline & Tertiary education & $6(2.5)$ & $2(0.8)$ & $8(3.3)$ \\
\hline & Total & $199(82.6)$ & $42(17.4)$ & $241(100.0)$ \\
\hline \multirow{3}{*}{$\begin{array}{l}\text { Body mass index } \\
\text { (BMI) }\end{array}$} & Normal (BMI $\leq 25)$ & $11(9.8)$ & $4(3.6)$ & $15(13.4)$ \\
\hline & Above normal (BMI > 25) & $84(75.0)$ & $13(11.6)$ & $97(86.6)$ \\
\hline & Total & $95(84.8)$ & $17(15.2)$ & $112(100)$ \\
\hline \multirow{5}{*}{$\begin{array}{l}\text { Hypertension } \\
\text { levels }^{35}\end{array}$} & \multicolumn{3}{|c|}{ Mild (SBP: 140-159 mmHg; DBP: 90-99 mmHg) } & $76(31.7)$ \\
\hline & \multicolumn{3}{|c|}{ Moderate (SBP: $160-179 \mathrm{mmHg}$; DBP: $100-109 \mathrm{mmHg}$ ) } & $34(14.2)$ \\
\hline & \multicolumn{3}{|c|}{ Severe (SBP: $\geq 180 \mathrm{mmHg} ; \mathrm{DBP}: \geq 110 \mathrm{mmHg}$ ) } & $19(7.9)$ \\
\hline & \multicolumn{3}{|c|}{ Controlled (SBP: $<140 \mathrm{mmHg}$; DBP: $<90 \mathrm{mmHg}$ ) } & $111(46.3)$ \\
\hline & \multicolumn{3}{|l|}{ Total } & $240(100)$ \\
\hline \multirow{4}{*}{$\begin{array}{l}\text { Blood pressure } \\
\text { (BP) }\end{array}$} & \multicolumn{3}{|l|}{ Median (Q1;Q3) systolic BP } & $140(120 ; 155)$ \\
\hline & \multicolumn{3}{|l|}{ Mean (SD) systolic BP } & $139.0(22.5)$ \\
\hline & \multicolumn{3}{|l|}{ Median (Q1;Q3) diastolic BP } & $80.0(74 ; 90)$ \\
\hline & \multicolumn{3}{|l|}{ Mean (SD) diastolic BP } & $81.1(12.5)$ \\
\hline \multirow{4}{*}{$\begin{array}{l}\text { History of } \\
\text { hypertension }\end{array}$} & \multicolumn{3}{|l|}{ Known family history } & $121(48.6)$ \\
\hline & \multicolumn{3}{|l|}{ No family history } & $92(51.4)$ \\
\hline & \multicolumn{3}{|c|}{ Did not know whether family history or not } & $36(14.5)$ \\
\hline & \multicolumn{3}{|c|}{ Total } & $249(100)$ \\
\hline \multirow[t]{2}{*}{ Co-morbidity } & \multicolumn{3}{|l|}{ Co-morbidity } & $121(51.3)$ \\
\hline & \multicolumn{3}{|l|}{ No co-morbidity } & $115(48.7)$ \\
\hline
\end{tabular}


\begin{tabular}{|l|l}
\hline & Totals \\
\hline *Percentage of total sample; Data for some patients were not available, hence difference in sample size
\end{tabular}

BP: Blood pressure; BMI: Body mass index SD: Standard deviation; Q: Quartile. SBP: systolic blood pressure, DBP diastolic blood pressure

\subsection{Hypertension, family history and co-morbidities}

More than half $(59.5 \%)$ of the patients had been on treatment for hypertension for more than five years, with only $46.3 \%$ of the patients presenting on the day of the interview with controlled hypertension (Table 1).

Nearly half (48.6\%) of the patients indicated they have a family history of hypertension, while $14.5 \%$ did not know whether they have a family member with hypertension or not. Half of the patients who reported a family history of hypertension (49.6\%), had a mother with hypertension. Co-morbidities were present in approximately half of the patients, of whom approximately half had diabetes as a co-morbidity (Table1).

\subsection{Knowledge of hypertension as a chronic condition}

Table 2 presents a summary of patients' knowledge of various aspects of hypertension by level of education. Less than a quarter $(18.75 \%)$ of the patients knew what normal BP should be, with significantly more who knew having some form of education $(83.3 \% ; p<0.001)$ compared to those without formal education (16.7\%). Similarly, significantly more patients with formal education $(68.4 \% ; \mathrm{p}=0.013)$ knew the definition of high BP. At least $50 \%$ of patients knew what causes hypertension and of those, $58.3 \%$ had formal education $(p<0.001)$. Some of the patients (13.4\%) did not know that high BP is dangerous to their health and $9.4 \%$ did not know the dangers of uncontrolled high BP.

The following verbatim quotations illustrate patients' lack of knowledge or misperception about the causes of hypertension:

"I don't know because for me it came when I was sleeping."

[62 year old female; no education; SBP: $138 \mathrm{mmHg}$ and DBP: $83 \mathrm{mmHg}$ ]

"As you grow older and stop menstruating."

[Female; SBP: $160 \mathrm{mmHg}$ and DBP: $80 \mathrm{mmHg}$; no education]

"Working in dusty places."

[64 years old male; SBP: $124 \mathrm{mmHg}$ and DBP: $64 \mathrm{mmHg}$; completed primary education]

The following statement shows that patients had some counselling on the causes of hypertension, though does not necessarily imply that the patient had hypertension as a result of taking contraceptives.

"Contraceptives."

[67 year old female; SBP: $160 \mathrm{mmHg}$ and DBP: $60 \mathrm{mmHg}$; no education] 
Table 2: Hypertension specific knowledge per educational level

\begin{tabular}{|c|c|c|c|c|c|c|c|c|c|}
\hline \multirow{4}{*}{ Knowledge related to hypertension } & \multirow{4}{*}{$\mathbf{N}^{*}$} & \multirow{4}{*}{$\begin{array}{c}\begin{array}{c}\text { Patients } \\
\text { with } \\
\text { knowledge }\end{array} \\
\text { No (96) }\end{array}$} & \multicolumn{7}{|c|}{ Patients with knowledge distributed by education } \\
\hline & & & \multirow{3}{*}{$\mathbf{n}^{*}$} & \multicolumn{4}{|c|}{ With education } & \multirow[t]{2}{*}{$\begin{array}{c}\text { Without } \\
\text { education }\end{array}$} & \multirow[t]{2}{*}{ P-value ${ }^{s}$} \\
\hline & & & & $\begin{array}{c}\text { Primary } \\
\text { completed }\end{array}$ & $\begin{array}{l}\text { Secondary } \\
\text { completed }\end{array}$ & $\begin{array}{c}\text { Tertiary } \\
\text { completed }\end{array}$ & Sub-total & & \\
\hline & & & & No $(\%)$ & No $(\%)$ & No $(9)$ & No $(9)$ & No $(9 \%)$ & \\
\hline \multicolumn{10}{|l|}{ Knowledge of hypertension as a chronic disease } \\
\hline Normal BP & 224 & $42(18.75)$ & 42 & $16(38.1)$ & $12(28.6)$ & $7(16.7)$ & $35(83.3)$ & $7(16.7)$ & $<0.001$ \\
\hline Definition of high BP & 229 & $38(16.0)$ & 38 & $14(36.8)$ & $9(23.7)$ & $3(7.9)$ & $26(68.4)$ & $12(31.6)$ & 0.013 \\
\hline Causes of BP & 240 & $120(50.0)$ & 120 & $44(36.7)$ & $21(17.5)$ & $5(4.2)$ & $90(58.3)$ & $50(41.7)$ & $<0.001$ \\
\hline Hyperteusion is dangerous & 243 & $212(87.2$ & 212 & $61(28.8)$ & $25(11.8)$ & $10(4.4)$ & $96(45.3)$ & $116(54.7)$ & 0.687 \\
\hline Dangers of uncontrolled high BP & 234 & $208(88.9)$ & 208 & $63(30.3)$ & $30(14.4)$ & $10(4.8)$ & $103(49.5)$ & $105(50.5)$ & 0.051 \\
\hline \multicolumn{10}{|l|}{ Knowledge of blood pressure measurement } \\
\hline How BP readings are recorded & 242 & $93(38.4)$ & 93 & $36(38.7)$ & $23(24.7)$ & $9(9.7)$ & $68(73.1)$ & $25(26.9)$ & $<0.001$ \\
\hline Importance of BP numbers & 236 & $10(4.2)$ & 10 & $4(40.0)$ & $2(20.0)$ & $0(0.0)$ & $6(60)$ & $4(40.0)$ & 0.579 \\
\hline Meaning of BP numbers & 240 & $5(2.1)$ & 5 & $3(60.0)$ & $2(40.0)$ & $0(0.0)$ & $5(100)$ & $0(0.0)$ & 0.047 \\
\hline \multicolumn{10}{|l|}{ Knowledge of the treatment of hvpertension with medicines } \\
\hline Taling antihypertensive medicines as prescribed is necessary & 240 & $237(98.8)$ & 237 & $69(29.1)$ & $31(13.1)$ & $10(4.2)$ & $110(46.4)$ & $127(53.6)$ & 0.077 \\
\hline Benefits of taling antihypertensive medicines correctly & 221 & $185(83.7)$ & 185 & $57(30.9)$ & $22(12.6)$ & $10(5.4)$ & $89(48.1)$ & $96(51.9)$ & 0.876 \\
\hline \multicolumn{10}{|l|}{ Knowledge of lifestyle modification } \\
\hline Erercise is necessary to control bigh BP & 231 & $222(96.1)$ & 222 & $64(28.8)$ & $30(13.5)$ & $10(4.5)$ & $104(46.8)$ & $118(53.2)$ & 0.554 \\
\hline Smoling is dangerous to hypertensive patients & 233 & $223(95.7)$ & 223 & $66(29.6)$ & $29(13.0)$ & $10(4.5)$ & $105(47.1)$ & $118(529)$ & 0.217 \\
\hline Alcohol is dangerous to byperteusive patients & 233 & $222(95.3)$ & 222 & $66(29.7)$ & $28(12.6)$ & $10(4.5)$ & $104(46.8)$ & $118(53.2)$ & 0.193 \\
\hline Can do something to lower BP & 243 & $114(46.9)$ & 114 & $42(36.8)$ & $16(14.0)$ & $7(6.1)$ & $65(57.0)$ & $49(43.0)$ & 0.007 \\
\hline
\end{tabular}

\subsection{Knowledge of blood pressure measurement}

A third (38.4\%) of the patients knew how BP readings are recorded, and of those, $73.1 \%$ $(\mathrm{p}<0.001)$ had some form of education. Only 10 patients $(4.2 \%)$ knew that both systolic and diastolic blood pressure recordings are important to indicate whether BP is controlled or not, and only five patients $(2.1 \%)$ knew the meaning of the numbers reported for BP, of whom all had some form of formal education $(\mathrm{p}=0.047)$ (Table 2$)$.

\subsection{Knowledge of the treatment of hypertension with medicines}

The majority of patients $(98.8 \%)$ knew that taking anti-hypertensive medicines as prescribed is important to control BP and $83.7 \%$ knew the benefits of taking these medicines correctly.

\subsection{Lifestyle practices}

A minority of patients (4.3\%) did not know that smoking is dangerous to health and $4.7 \%$ did not know that excessive alcohol is dangerous to hypertensive patients (Table 2).

Table 3 presents patients' social lifestyle habits as reported during the interview, i.e. physical activity, use of alcohol and smoking. More than half (59.8\%) of the patients indicated that they were doing some form of physical activity, of which the most common activity was playing soccer. Another common activity was jogging; however, the frequency of jogging was not well explained. Very few (3.6\%) patients indicated that they consumed alcohol, and only $11.6 \%$ indicated that they were smoking, either cigarettes or snuff. Of the 29 patients who confirmed that they were smoking, nine indicated they smoked one to five cigarettes per day. 
Table 3: Patients' lifestyle practices

\begin{tabular}{|c|c|c|c|}
\hline \multirow{2}{*}{\multicolumn{2}{|c|}{ Lifestyle practices }} & \multirow{2}{*}{$\mathbf{n}$} & Patients \\
\hline & & & No (\%) \\
\hline \multicolumn{2}{|c|}{ Participate in physical activity } & 249 & $149(59.8)$ \\
\hline \multicolumn{2}{|l|}{ Use alcohol } & 250 & $9(3.6)$ \\
\hline \multirow[t]{4}{*}{ Frequency of alcohol use* } & 2-3 per week & 9 & $1(11.1)$ \\
\hline & 2-4 per week & 9 & $4(44.4)$ \\
\hline & $4+$ per week & 9 & $1(11.1)$ \\
\hline & Monthly or less & 9 & $3(33.4)$ \\
\hline \multicolumn{2}{|l|}{ Smoke cigarettes or snuff } & 251 & $29(11.6)$ \\
\hline \multirow{4}{*}{ Frequency of smoking } & $1-5$ per day & 29 & $9(31.0)$ \\
\hline & 6-10 per day & 29 & $3(10.3)$ \\
\hline & Varies & 29 & $2(6.9)$ \\
\hline & No data & 29 & $14(48.3)$ \\
\hline
\end{tabular}

*Number of times per week or month alcohol is consumed, without specifying the units of alcohol or the number of drinks.

\subsection{Knowledge of lifestyle modification}

Less than half of the patients indicated that they were aware of the fact that they can do something such as exercise to help control their BP (Table 2). Table 4 presents the lifestyle modification as reported by these patients. Half of these indicated that to reduce, or stop, salt intake can reduce high BP. Nearly a third indicated that reducing stress can assist with reducing high BP. A few (13.2\%) mentioned other activities such as limiting sugar intake, going to church or praying, stopping smoking and alcohol, eating grape fruit and talking to doctors (Table 4).

Table 4: Knowledge of lifestyle modification which can reduce high BP

\begin{tabular}{|l|c|c|}
\hline \multirow{2}{*}{ Lifestyle modification } & \multicolumn{2}{c|}{ Patients* } \\
\cline { 2 - 3 } & n & No. (\%) \\
\hline Reduce or stop salt intake & 114 & $58(50.9)$ \\
\hline Avoid stress or always be happy & 114 & $35(30.7)$ \\
\hline Taking medicines correctly and on time & 114 & $28(24.6)$ \\
\hline Exercise or jogging & 114 & $24(21.1)$ \\
\hline Drink a lot of water & 114 & $22(19.3)$ \\
\hline Avoid fatty food & 114 & $17(14.9)$ \\
\hline Eat bitter vegetables & 114 & $11(9.6)$ \\
\hline Others & 114 & $15(13.2)$ \\
\hline
\end{tabular}

*More than one response per patient possible

\subsection{Hypertension information}

The sample size (n) refers to the number of patients from whom data were available. More than half $(56.0 \% ; 136, \mathrm{n}=244)$ of the patients indicated that they received information regarding hypertension at the PHC facilities during their consultation or when collecting their antihypertensive medication. However only $47.1 \%(64, \mathrm{n}=136)$ could specify what kind of information they received (see Figure 1). Information most commonly referred to address lifestyle practices. This included information on diet $(37.5 \%, 24, \mathrm{n}=64)$, lifestyle $(31.3 \%, 20$, $\mathrm{n}=64)$, and BMI $(1.6 \%, 1, \mathrm{n}=64)$. Only $15.6 \%(10, \mathrm{n}=64)$ of the patients indicated that they received specific information on anti-hypertension medicines. Dangers and complications, signs and symptoms, and hypertension in general was mentioned by less than $10 \%$ of patients and $7.8 \%(5, n=54)$ of patients indicated that they could not remember what information they received (Figure1). 
Figure 1: Hypertension information received $(\mathrm{n}=64)$

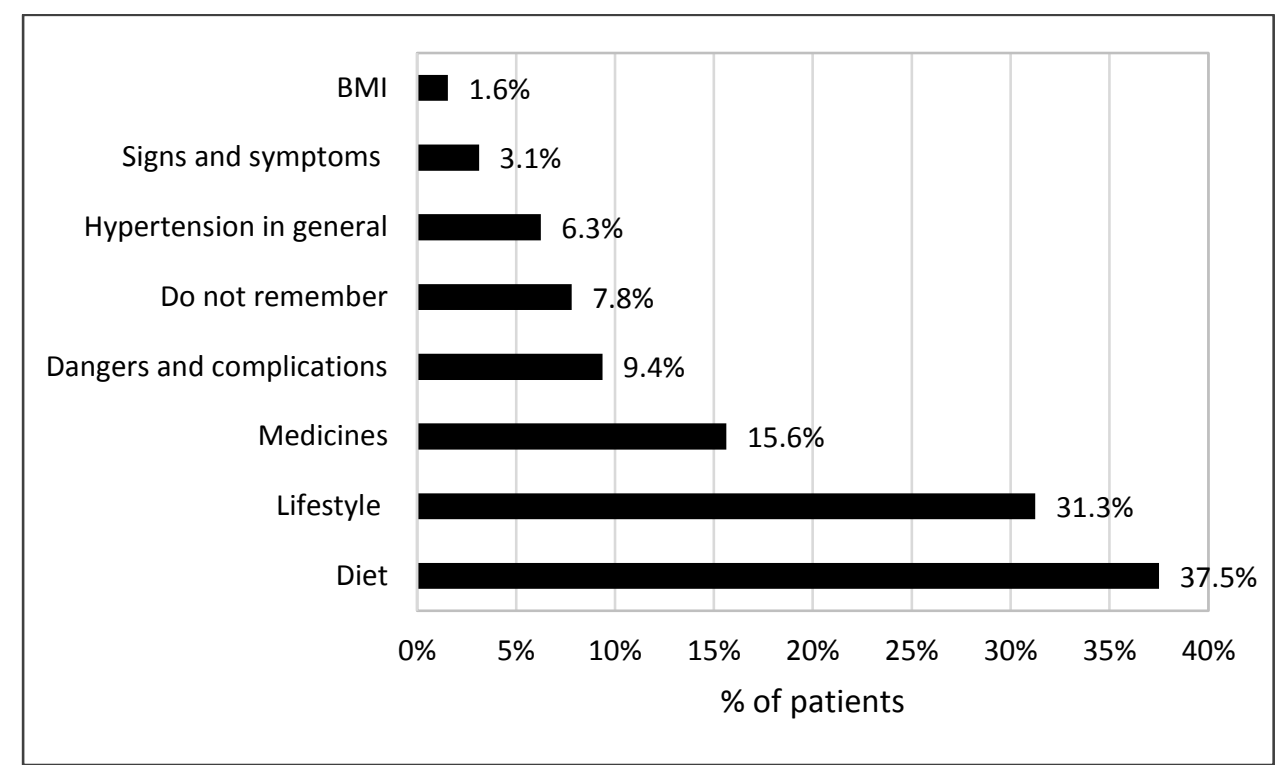

Note: Some patients mentioned more than one item

The vast majority $(95 \%, 232, \mathrm{n}=244)$ of patients indicated that they needed more information about hypertension, of whom only half $(51.7 \%, 120, \mathrm{n}=232)$ indicated what information they needed. Most $(70.8 \%, 85, \mathrm{n}=120)$ indicated the need for information about hypertension in general. Almost a quarter, who could specify the information they received, indicated the need to receive more information on lifestyle changes $(23.3 \%, 28, \mathrm{n}=120)$, with only $5.0 \%(6$, $\mathrm{n}=120)$ indicating the need for information on hypertension medication and $2.5 \%(3, \mathrm{n}=120)$ not being sure of what information they need (Figure 2).

Figure 2: Hypertension information patients would like to receive $(n=120)$

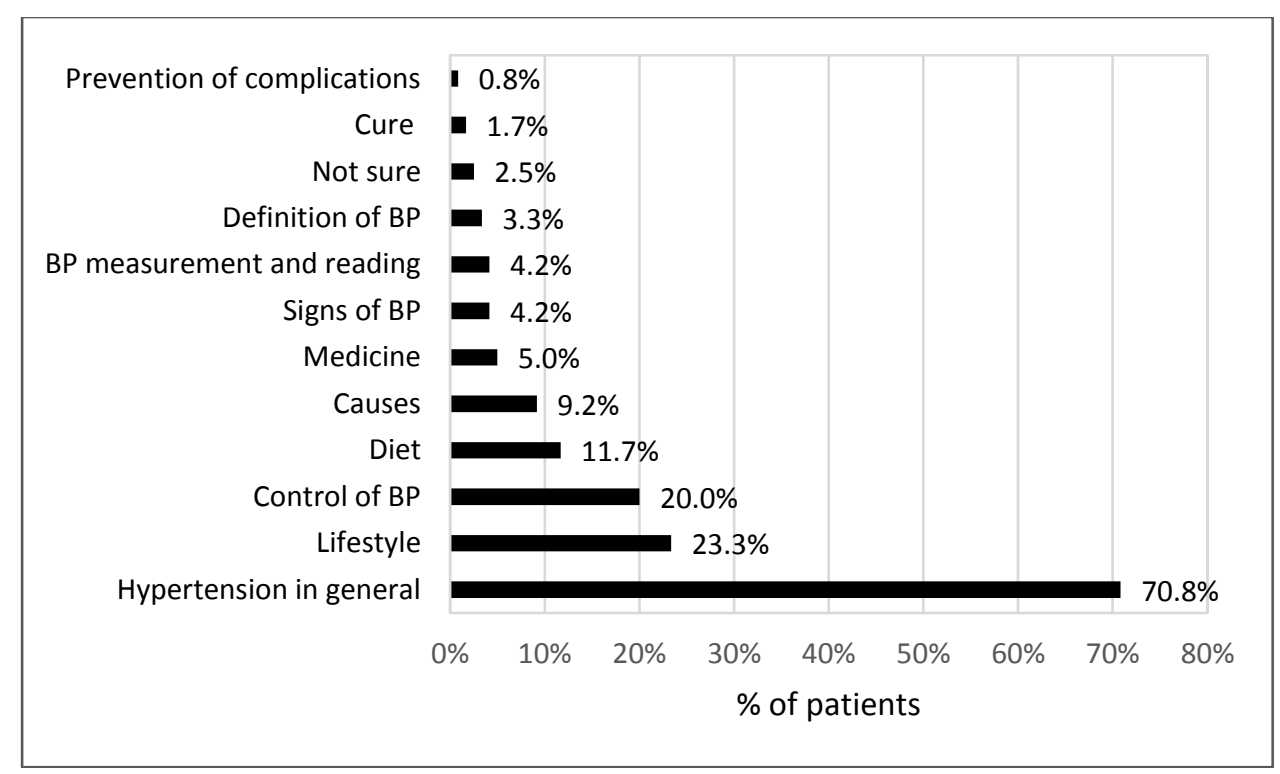




\section{Discussion}

This study explored the knowledge of hypertension and its management among 253 chronic hypertensive patients in SA. The majority (81.9\%) of patients were female, and more than half were older than 60 years with a mean age of 62.7 (SD:13.63) years (Table 1). This is consistent with studies previously conducted in South Africa and Botswana [11,19,32-34]. This is important as the prevalence of hypertension in this group may be related to aging $[3,32]$. Less than half of the patients $(46.3 \%)$ in this study had controlled hypertension (SBP $<140 \mathrm{mmHg}$ and DBP $<90 \mathrm{mmHg}$ ) as per the South African Standard Treatment Guidelines [35] (Table 1), consistent with previous studies in SA and in Pakistan [22,33].

Half of the patients had a family history of hypertension (Table 1), and in the vast majority of these patients, this was on the mother's side. This suggests the possibility that hypertension in these patients is genetic on the maternal side, consistent with previous studies in SA and Botswana $[19,33,34]$. Higher prevalence rates among women could also be related to a higher prevalence of obesity among women in SA compared to men $[9,36]$.

More than half of the patients did not have any formal education (Table 1), and less than a quarter of those who had some form of education had a tertiary qualification. This high rate of illiteracy is a concern if only typed instructions are given to patients. Without formal education, coupled with lack of health care literacy about hypertension including how to manage it and appropriate lifestyle changes, as well as not remembering what information has been received (Tables 2 and 4, Figure 1), similar to other studies [3,32,37], this can impact negatively on BP control [21-26], increasing the rate of uncontrolled hypertension. This contributes to the high rates of uncontrolled hypertension seen in our study (Table 1). Consequently, health care practitioners need to continuously assess hypertensive patients' knowledge to address key knowledge gaps with appropriate information including oral information. The latter is important given the high illiteracy rate in these patients.

Encouragingly, the majority of patients knew that hypertension is dangerous to their health and that taking antihypertensive medication as prescribed, or advised by the pharmacist, is necessary to control their BP (Table 2). This is similar to a study conducted in Nigeria [29]. This suggests that patients are likely to comply with their medicines with increasing knowledge about the benefits of taking their medicines, similar to other studies [21-25]. Overall, increasing patients' knowledge can improve hypertension management [20-22].

Of concern is that less than half of the patients could explain what high BP is despite an appreciable number of patients on treatment for five years or longer (Table 2). Very few patients were aware as to how BP readings are recorded in their files and understood the meaning of the numbers. In addition, only a few patients knew what normal BP should be, an indication that patients did not know their treatment target, which can contribute to uncontrolled BP, similar to previous studies conducted in China and SA $[21,38]$.

Encouragingly as well, more than half of the patients were aware of the fact that social habits are also associated with BP control (Table 2) and were involved in some form of physical activity (Table 3 ). Most of the patients were also not consuming alcohol and were not smoking (Table 3). Half of the patients indicated reducing or stopping salt intake can assist in reducing high BP, which is also encouraging (Table 4). However, other factors such as avoiding stress and fatty foods were considerably less well known (Table 4). Consequently, knowledge on possible social habits and lifestyle modifications needs to be improved to help further control 
hypertension alongside education generally of the disease [23,25,37,39]. This will help address the finding that the majority of patients in our study indicated the need to receive more information about hypertension and its management. Nearly three quarters of patients indicated a need to receive more information on hypertension in general, followed by the need for information on lifestyle changes (Figure 2). The appreciable difference in percentages of patients who need different types of information on hypertension (Figure 2) could be linked to the possibility that these patients are not receiving the appropriate information about hypertension in the first place. Consequently, as mentioned, it is important for all health care providers in PHC facilities continuously assess hypertensive patients' understanding and knowledge of their disease. Whilst few patients indicated the need for information on hypertensive medicines (Figure 1), a number of them were not sure what kind of information they received. This again is an indication that hypertensive patients should receive educational information regularly [39-41]. In view of this, there is a need to improve on the mode of delivering hypertension information at PHC clinics in SA especially with issues such as access being resolved with the NHI system and CCMDD programmes, which has been a concern in some countries and centres [42]. This is especially important in patients with limited or no education who cannot read or interpret instructions [23-25,42].

Considering pharmacists' training and scope of practice [43], they are well-positioned to develop and implement strategies along with physicians to improve patients' knowledge on hypertension and its management to subsequently improve treatment outcomes [16,44-48]. The pharmacist's role could be to help verify that patients can demonstrate sufficient knowledge and skills to follow their pharmacotherapeutic regimens and monitoring plans, as well as motivate them to learn about their treatment and actively participate in their own care [49]. In addition, pharmacists could also participate generally to improve health care literacy [49-51]. This is imperative given the high and growing public health burden of NCDs including hypertension in SA. The introduction of the NHI system with the re-engineering of PHC services, including the CCMDD programme, creates the ideal opportunity for this [13].

We are aware of the limitations in this study. These include the fact that the study was only conducted in one province of SA. For some of the questions, data were missing, which affected the sample size for these questions. However, in view of the importance of this province and district, as an NHI pilot site and part of the CCMDD programme, we believe that the findings are robust and can provide direction to the authorities as they progress with the CCMDD programmes to reduce the morbidity and mortality of NCDs in SA.

\section{Conclusion}

Although the majority of the patients in this study had basic knowledge on hypertension, they lacked hypertension specific knowledge such as knowledge about what hypertension is, what the normal BP should be, that both systolic and diastolic readings are important, and what activities can be undertaken such as exercise to better control BP. This is a concern as the Vhembe District is one of the NHI pilot districts in which the CCMDD programme is being implemented. Consequently, it is imperative to develop educational intervention strategies among PHC facilities, to conduct research on the development and piloting of such activities, and to address knowledge gaps. Co-ordinated programmes are important to improve the management of patients with chronic diseases already in the CCMDD programme and those still to be registered on the programme, given the prevalence of hypertension in South Africa. The results showed that there is a need to continuously give hypertension information to patients to empower them with specific knowledge on hypertension. Pharmacists can be part 
of this programme. This is important as more low and middle income countries strive to provide universal access of care to patients, especially those with chronic NCDs such as hypertension.

\section{Executive Summary}

- Half of patients had uncontrolled hypertension despite an appreciable number on treatment for five years or more, which is a concern given the high prevalence rates of hypertension in South Africa

- There is typically a lack of literacy and formal education among patients seeking care at PHC facilities in South Africa and wider. As a result, it is important that verbal instructions are given alongside any written instructions, and multi-disciplinary teams are involved so messages are repeated, to improve medicine taking and adherence as well as lifestyle changes

- The majority of patients knew that hypertension is dangerous to health; however limited knowledge of BP numbers, except among the educated, and their rationale

- Patients were aware that reducing salt intake would help reduce hypertension but not factors such as avoiding stress or fatty foods. This needs addressing

- More needs to be done in South Africa as it rolls out its Central Chronic Medicines Dispensing and Distribution (CCMDD) programme to improve the availability and accessibility of medicines to patients with chronic diseases to ensure the morbidity and mortality from hypertension is reduced from current high levels

\section{Acknowledgements}

The authors thank all the patients for their time and willingness to participate in this study. Special appreciation goes to the PHC facilities' personnel for their support and the following pharmacists who assisted with the data collection: Ms RG Dleve, Ms LP Mathabi, Mr NJ Tsita, Mr VA Mathonsi, Ms N Netshiavha, Ms MC Masingi, Mr TC Raphiri, Ms I Tauatswala, Ms P Maluleke, Ms Chauke and Ms T Raulisa. Prof HS Schoeman is acknowledged for his assistance with the statistical analysis of the data.

\section{Conflict of interest and funding}

The authors hereby declare that they have no conflicts of interest to disclose.

\section{Author contributions}

EMR, JCM and EH conceptualized and developed the research, initiated the research and performed data analysis. EMR, JCM BBG edited and appraised the paper during the various stages of production. All authors approved and permitted the submission of this paper to this journal.

\section{References}

1. World Health Organization. Noncommunicable diseases. Fact sheet 2017. Available at URL: http://www.who.int/mediacentre/factsheets/fs355/en/

2. Maimela E, Alberts M, Modjadji SEP et al. The prevalence and determinants of chronic non-communicable disease risk factors amongst adults in the Dikgale health demographic and surveillance system (HDSS) Site, Limpopo Province of South Africa. PloS ONE 2016;11.

3. Ofili MI, Ncama BP, Sartorius B. Hypertension in rural communities in Delta State, Nigeria: Prevalence, risk factors and barriers to health care. Afr J Prim Health Care Fam Med 2015; 7:875. 
4. GACD Hypertension Research Programme, Writing Group, Peiris D, Thompson SR et al. Behaviour change strategies for reducing blood pressure-related disease burden: Findings from a global implementation research programme. Implementation Sci 2015; 0:158. doi:10.1186/s13012-015-0331-0.

5. GETTY. A global brief on hypertension | foreword. 2013. Available from: http://apps.who.int/iris/bitstream/10665/79059/1/WHO_DCO_WHD_2013.2_eng.pdf (Accessed: 29 January 2017).

6. Irazola VE, Gutierrez L, Bloomfield $\mathrm{G}$ et al. Hypertension prevalence, awareness, treatment, and control in selected LMIC communities: Results from the NHLBI/UHG network of centers of excellence for chronic diseases. Global Heart Journal 2016;11(1):47-59.

7. Nielsen JO, Shrestha AD, Neupane D, Kallestrup P. Non-adherence to antihypertensive medication in low- and middle-income countries: a systematic review and meta-analysis of 92443 subjects. Journal of human hypertension 2017;31(1):1421.

8. Lalkhen H, Mash R. Multimorbidity in non-communicable disease in South African primary healthcare. S Afr Med J 2015;105(2):134-138.

9. Cois A, Day C. Obesity trends and risk factors in the South African adult population. BMC Obesity 2015; Oct 13;2:42.

10. Lloyd-Sherlock P, Beard J, Minicuci N, Ebrahim S, Chatterji S. Hypertension among older adults in low- and middle-income countries: prevalence, awareness and control. Int J Epidemiol 2014; 43(1):116-128

11. Statistics South Africa (Stats-SA). Mortality and causes of death in South Africa, 2015: Findings from death notification. Statistical release P0309.3. Available from: http://www.statssa.gov.za/publications/P03093/P030932015.pdf (Accessed 5 April 2017).

12. Mash B, Fairall L, Adejayan O et al. A Morbidity Survey of South African Primary Care. PLoS ONE 2012;7(3).

13. Bradley H, Sanders D, Beekie A. Public Health: Every pharmacist's business! S Afr Pharm J 2011;78(10).

14. Jolles EP, Padwal RS, Clark AM, Braam B. A qualitative study of patient perspectives about hypertension. Int Sch Res Notices. 2013; ID671691. 10 pages.

15. Mungal-Singh V. Lifestyle changes for hypertension. S Afr Fam Pract. 2012;54 (2) Suppl 1:S12-S16.

16. Mant J, McManus RJ. Does it matter whether patients take their antihypertensive medication as prescribed? The complex relationship between adherence and blood pressure control. J Hum Hypertens 2006;20(8):551-3.

17. Corrao G, Parodi A, Nicotra F et al. Better compliance to antihypertensive medications reduces cardiovascular risk. J Hypertens 2011;29(3):610-8.

18. Cramer JA, Benedict A, Muszbek N, Keskinaslan A, Khan ZM. The significance of compliance and persistence in the treatment of diabetes, hypertension and dyslipidaemia: A review. Int J Clin Pract 2008;62(1):76-87.

19. Ramaano NS, Tugli AK, Akinsola HA, Ramathuba D. Socio-economic characteristics and pre-disposing factors contributing to high blood pressure among hypertensive patients at Folovhodwe village, Limpopo Province, South Africa. Afr J Phy Health Educ Recreat Dance 2014;20(4):1342-1352.

20. Dennison RC, Peer M, Steyn K, Levitt NS, Hill MN. Determinants of hypertension care and control among Peri-Urban Black South Africans: The HIHI Study. Ethn Dis 2009;17(3):484-49. 
21. Nkosi NG, Wright SCD. Knowledge related to nutrition and hypertension management practices of adults in Ga-Rankuwa. Curationis 2010 Jun;33(2):33-40.

22. Almas A, Godi SS, Lalani S, Samani ZA, Khan AH. Good knowledge about hypertension is linked to better control of hypertension; A multicentre cross sectional study in Karachi, Pakistan. BMC 2012;5:579.

23. Patel S, Dowse R. Understanding the medicines information-seeking behaviour and information needs of South African long-term patients with limited literacy skills. Health Expect 2015 Oct;18(5):1494-507.

24. Adebolu FA, Naidoo M. Blood pressure control amongst patients living with hypertension presenting to an urban district hospital outpatient clinic in KwazuluNatal. Afr J Prim Health Care Fam Med 2014;6(1), 6 pages.

25. Okwuonu CG, Ojimadu NE, Okaka EI, Akemokwe FM. Patient-related barriers to hypertension control in a Nigerian population. Int J Gen Med 2014;7:345-353.

26. Boima V, Ademola AD, Odusola AO et al. Factors associated with medication nonadherence among hypertensives in Ghana and Nigeria. Int J Hypertens 2015; 2015.ID205716, 8 pages.

27. Republic of South Africa for South Africa. Towards universal health coverage. 2015. Available from:

http://www.gov.za/sites/www.gov.za/files/National_Health_Insurance_White_Paper_ 10Dec2015.pdf.

28. Health System Trust. 2015. Central chronic medicines dispensing and distribution programme (CCMDD). Available from: http://www.hst.org.za/projects/centralchronic-medicine-dispensing-and-distribution-programme-ccmdd.

29. Iyalomhe BS, Iyalomhe SI. Hypertension-related knowledge, attitudes and life-style practices among hypertensive patients in a sub-urban Nigerian community. $\mathrm{J}$ Epidemiol Public Health 2010 Jul;2(4):71-77.

30. Edo TA. Factors affecting compliance with anti-hypertensive drug treatment and required lifestyle modifications among hypertensive patients on Praslin Island. 2009. Available from: http://uir.unisa.ac.za/handle/10500/3249.

31. Oliveria SA, Chen RS, McCarthy BD, Davis CC, Hill MN. 2005. Hypertension knowledge, Awareness, and attitudes in a hypertensive population. Journal of General Internal Medicine 2005; 20(3):219-225. doi:10.1111/i.1525-1497.2005.30353.x. Available from: https://www.ncbi.nlm.nih.gov/pmc/articles/PMC1490067/.

32. Magawa R. Primary health care implementation: A brief review. Public health discussion paper, Consultancy Africa Intelligence 2012. Available from: http://www.consultancyafrica.com/index.php? (Accessed 18 October 2016).

33. Rayner B, Schoeman HS. A cross-sectional study of blood pressure control in hypertensive patients in general practice (the 1-TARGET study). Cardiovasc J Afr 2009;20(4):224-227.

34. Zungu LI, Djumbe FR, Setswe KG. Knowledge and lifestyle practices of hypertensive patients attending a primary health care clinic in Botswana. Afr J Phy Health Educ Recreat Dance 2013; Suppl. 1:123 - 138.

35. National Department of Health (NDoH). Standard Treatment Guidelines and Essential Medicines List for South Africa. Pretoria: NDoH; 2014. Available at URL: http://www.kznhealth.gov.za/pharmacy/edlphc2014a.pdf.

36. Mchiza ZJ, Parker W, Makoae M, Sewpaul R, Kupamupindi T. Body image and weight control in South Africas 15 years or older: SANHANES-1. BMC Public Health 2015;15:992.

37. Aubert L, Bovet P, Gervasoni J, Rwebogora A, Waeber B, Paccaud F. Knowledge, attitudes, and practices on hypertension in a country in 
epidemiological transition. Dallas. Hypertension, American Heart Association 1998; 31(5):1136-1145.

38. Wang Y, Kong D, Ma L, Wang L. Patient related factors for optimal blood pressure control in patients with hypertension. Afr Health Sci 2013;13(3):579583.

39. Dawes MG, Kaczorowski J, Swanson G, Hickey J, Karwalajtys T. The effect of a patient education booklet and BP tracker on knowledge about hypertension: A randomized controlled trial. Fam Pract. 2010;27(5):472-478.

40. Arul KSG, Julie KY, Jijie J, Palanisamy S, Shaise J. Development and Implementation of Patient Information Leaflet on Hypertension and to Assess its Effectiveness. Int J Pharm Tech Res 2009;1(3):712-719.

41. Mpinda J, Tumbo J, Govender I, Mills B. The knowledge and beliefs of hypertensive patients attending Katleho District Hospital in Free State province, South Africa, about their illness. S Afr Fam Pract. 2014;56(4):1-6.

42. Thinyane KH, Mothebe T, Sooro M, Namole LD, Cooper V. An observational study of hypertension treatment and patient outcomes in a primary care setting. The Pan African medical journal 2015;20:424.

43. Fikri-Benbrahim N, Faus MJ, Martinez-Martinez F, Sabater-Hernandez D. Impact of community pharmacists' hypertension-care service on medication adherence. The AFenPA study. Research in Social \& administrative Pharmacy, RSAP 2013; 9(6):797-805. doi:10.1016/j.sapharm.2012.12.006.Epub2013Feb4.

44. South African Pharmacy Council. Good Pharmacy Practice in South Africa. 4th Edition. Pretoria, South African Pharmacy Council, 2010.

45. George MG, Gunn J. Hypertension prevention, treatment, control and sodium reduction policy. US department of health and human services 2012. Available from:

http://www.medicinedocshare.com/htm/2_Swf_Prevention_treatment_Control_an d Sodium_Reduction_Policy_36543.

46. Bunting BA, Smith BH, Sutherland SE. The Asheville Project: Clinical and economic outcomes of a community-based long-term medication therapy management program for hypertension and dyslipidaemia. Journal of the American Pharmacists Association : JAPhA 2008; 48(1):23-31. doi:10.1331/JAPhA.2008.07140.

47. Alexander MR, Yang EH, Madhur MS, Harrison DG, Dreisbach AW, Riaz K.. Hypertension treatment \& management: Approach considerations, nonpharmacologic therapy, pharmacologic therapy. The Heart.org Mediscape (2017). Available from: http://emedicine.mediscape.com/article/241381-treatment.

48. Rigby D. Collaboration between doctors and pharmacists in the community. Australian Prescriber 2010; 33(6):191-193. doi:10.18773/austprescr.2010.088.

49. ASHP/BHH. Medication therapy and patient care: Organization and delivery of services-guidelines. 2016. Available from: http://www.ashp.org/DocLibrary/Bestpractice/OrgGdPtEduc.aspx.

50. Matowe L, Mori AT, Mawa S. Enhancing the role of pharmacists in public health in developing countries. Pharm J 2012; 288:623.

51. Rabkin S. Assessing and managing hypertension. BCMJ 2012; 54(8):390-391. 